\title{
INVISIBILIZADOS NA ILHA DO DESTERRO: OS NOVOS FLUXOS DE IMIGRANTES E REFUGIADOS EM FLORIANÓPOLIS
}

\author{
THE INVISIBLE ONES IN THE ISLAND OF DESTERRO: \\ THE NEW FLOWS OF IMMIGRANTS AND REFUGEES IN FLORIANÓPOLIS
}

\section{INVISIBILIZADOS EN LA ISLA DEL DESTERRO: LOS NUEVOS FLUJOS DE INMIGRANTES Y REFUGIADOS EN FLORIANÓPOLIS}

\author{
KARINE dE SOUZA SILVA \\ https://orcid.org/0000-0001-9212-8818 / http://lattes.cnpq.br/2759073114468670 / karine.silva@ufsc.br \\ Universidade Federal de Santa Catarina, UFSC. \\ Florianópolis, SC, Brasil.
}

\begin{abstract}
Carolina Nunes Miranda Carasek da Rocha
https://orcid.org/0000-0002-0000-7961 / http://lattes.cnpq.br/7404631442770520 / carolinacarasek@hotmail.com Universidade Federal de Santa Catarina, UFSC. Florianópolis, SC, Brasil.
\end{abstract}

LUCAS D'AVILA https://orcid.org/0000-0001-5012-9556 / http://lattes.cnpq.br/7483814703627147 / lucasdavilajj@gmail.com Universidade Federal de Santa Catarina, UFSC. Florianópolis, SC, Brasil.

\begin{abstract}
RESUMO
O objetivo deste artigo é identificar as peculiaridades dos recentes fluxos migratórios internacionais na Grande Florianópolis, cujas multiplicidades têm acarretado uma reconfiguração no perfil demográfico da capital catarinense. A pesquisa, realizada no período de 2015 a 2017, utilizou-se de métodos e técnicas de pesquisa qualitativa (análise documental) e quantitativa (cadastro institucional fechado). A investigação centrou-se no levantamento de informações e análise do perfil de uma amostra de 1783 imigrantes e refugiados atendidos pelo Projeto de Extensão “Cátedra Sérgio Vieira de Mello - Núcleo de Apoio a Imigrantes e Refugiados" da Universidade Federal de Santa Catarina, em parceria com a Pastoral do Migrante. Este estudo pioneiro no âmbito das atuais migrações na região mostrou, em última instância, que os imigrantes e refugiados não-brancos dos eixo sul-sul são invisibilizados e, devido à ausência de políticas públicas estaduais e municipais de integração e acolhimento, são submetidos a processos preocupantes de hiper-vulnerabilização.
\end{abstract}

Palavras-chave: Florianópolis. Imigrantes e Refugiados. Migrações sul-sul. Pastoral do Migrante/CSVM/Universidade Federal de Santa Catarina.

\section{ABSTRACT}

This work seeks to identify the peculiarities of the recent international migration flows to the region of Great Florianópolis, whose multiplicities have led to a reconfiguration of the demographic profile of the capital of Santa Catarina. The research, carried out in the period from 2015 to 2017, used methods and techniques of qualitative research (documental analysis) and quantitative research (closed institutional register). The investigation focused on the survey of information and analysis of profile of a sample of 1783 immigrants and refugees assisted by the Extension Project "Cátedra Sérgio Vieira de Mello: Immigrant and Refugee Support Center" from the Federal University 
of Santa Catarina, in partnership with Migrant's Pastoral. This pioneering study in the context of the current migrations in the region has shown, in the ultimate extent, that non-white immigrants and refugees from the southsouth axis are invisibilized and, due to the absence of state and municipal public policies of integration and reception, they are subject to worrying processes of hyper-vulnerability.

Keywords: Florianópolis. Immigrants and Refugees. Migrant's Pastoral/CSVM/Federal University of Santa Catarina. South-South Migrations.

\section{RESUMEN}

El objetivo de este artículo es identificar las peculiaridades de los recientes flujos migratorios internacionales de la Grand Florianópolis, cuyas multiplicidades tienen implicado en una reconfiguración en el perfil demográfico de la capital catarinense. La pesquisa, realizada en el período de 2015 a 2017, se utilizó de métodos e técnicas de pesquisa cualitativa (análisis documental) e cuantitativa (registro institucional cerrado). La investigación se centró en el levantamiento de informaciones y análisis del perfil de una muestra de 1783 inmigrantes y refugiados asistidos por el Proyecto de Extensión "Cátedra Sérgio Vieira de Mello: Centro de Apoyo a Inmigrantes y Refugiados" de la Universidad Federal de Santa Catarina, en sociedad con la Pastoral del Migrante. Este estudio pionero en el ámbito de las actuales migraciones en la región mostró, en última instancia, que los inmigrantes y refugiados no-blancos del eje sur-sur son invisibilizados y, debido a la ausencia de políticas públicas estaduales y municipales de integración y acogimiento, son sometidos a procesos preocupantes de hiper-vulnerabilización.

Palabras clave: Florianópolis. Inmigrantes y refugiados. Migraciones sur-sur. Pastoral del Migrante/CSVM/Universidad Federal de Santa Catarina.

\section{SUMÁRIO}

INTRODUÇÃO; 1 SANTA CATARINA: DOS PRIMEIROS IMIGRANTES AOS NOVOS FLUXOS MIGRATÓRIOS SULSUL; 1.1 Novos imigrantes na Grande Florianópolis; 2 PERFIL DOS IMIGRANTES E REFUGIADOS ATENDIDOS ENTRE 2015 A 2017; 2.1 Nacionalidades; 2.2 Escolaridade; 2.3 Gênero; 2.4 Faixa etária; 2.5 Demandas; 3 PARTICULARIDADES DOS NOVOS FLUXOS MIGRATÓRIOS E A CARÊNCIA DE POLÍTICAS PÚBLICAS; CONCLUSÃO; REFERÊNCIAS.

\section{INTRODUÇÃO}

Florianópolis, antigamente denominada Nossa Senhora do Desterro, tem sido, historicamente, um lugar de destino de imigrantes que, em diversos fluxos, somaram-se às populações nativas. Os diferentes movimentos migratórios têm alterado constantemente o perfil demográfico da cidade, ainda que as populações de origem europeia permaneçam sendo as majoritárias desde o início dos processos de colonização.

Os povos não-brancos do Sul Global, sejam os grupos autóctones ou os negros, embora em número minoritário, sempre estiveram presentes no mapa das etnias catarinenses. A novidade é que nas últimas décadas tem havido um aumento expressivo de imigrantes das nações periféricas e semiperiféricas, acompanhando o ingresso do Brasil no eixo sul-sul de migrações. Nessa nova configuração, o Sul do país, devido aos bons índices de desenvolvimento, tem se configurado como um polo atrativo. 
ISSN 1981-3694

(DOI): $10.5902 / 1981369433488$

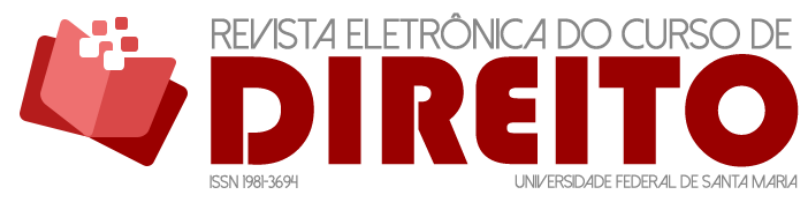

INVISIBILIZADOS NA ILHA DO DESTERRO: OS NOVOS FLUXOS DE IMIGRANTES E REFUGIADOS EM FLORIANÓPOLIS

KARINE DE SOUZA SILVA CAROLINA NunES MiRANDA CARASEK DA ROCHA LUCAS D'AVILA

Entretanto, essa nova fotografia não tem recebido a devida atenção dos Poderes Públicos catarinenses estaduais e municipais. Assim, as chegadas crescentes trazem a necessidade de reconhecer as singularidades dos fluxos migratórios recentes que esculpem uma nova faceta do universo populacional do estado de Santa Catarina e da região da Grande Florianópolis e, por conseguinte, impõem, em caráter urgente, a indispensabilidade de elaborar estratégias públicas eficazes em matéria de políticas migratórias.

De fato, os imigrantes e refugiados dos eixos sul-sul têm sido continuamente invisibilizados nesta região. Ao desconsiderar essas presenças, as entidades públicas enviam uma mensagem subliminar de que esses coletivos não são bem-vindos e nem fazem parte da população florianopolitana, e ao mesmo tempo se eximem da obrigação de formular políticas públicas estaduais e municipais de acolhimento e integração.

Diante desse cenário, este artigo objetiva identificar as peculiaridades dos recentes fluxos migratórios internacionais na Grande Florianópolis, cujas multiplicidades têm acarretado uma reconfiguração no perfil demográfico da capital catarinense. A metodologia utilizada abarcou os métodos e técnicas de pesquisa qualitativa (análise documental) e quantitativa (cadastro institucional fechado), e as análises foram orientadas pelas epistemologias decoloniais e pós-coloniais.

A pesquisa quantitativa utilizou a técnica de cadastro institucional fechado. 0 limite temporal estabelecido para o levantamento de informações e análises do perfil foi o triênio 2015 a 2017. Definiu-se, para tal, um grupo de amostragem circunscrito a 1783 imigrantes e refugiados entre os que foram atendidos no período pelo Projeto de Extensão "Cátedra Sérgio Vieira de Mello: Núcleo de Apoio a Imigrantes e Refugiados" da Universidade Federal de Santa Catarina, em parceria com a Pastoral do Migrante.

Esta pesquisa, inédita no âmbito das atuais migrações em Santa Catarina e na Grande Florianópolis, está estruturada em três partes. A primeira apresenta um breve relato historiográfico da migração para Santa Catarina. A segunda parte revela o perfil dos imigrantes atendidos no triênio 2015-2017 a partir de cinco categorias distintas: 1) nacionalidade; 2) escolaridade; 3) gênero; 4) faixa etária; e 5) demandas. Por fim, o último tópico exibe as peculiaridades dos recentes fluxos migratórios na região e denuncia a carência de políticas públicas estaduais e municipais para bem acolher os novos habitantes. 


\section{SANTA CATARINA: DOS PRIMEIROS IMIGRANTES AOS NOVOS FLUXOS MIGRATÓRIOS SUL-SUL}

O texto será escrito em letra Trebuchet tamanho 11 e com espaçamento 1,5 e justificado. Não deve haver espaço entre os parágrafos que compõem o texto, nem espaçamento automático gerado pelo processador de texto.

O estado de Santa Catarina (SC) é reconhecido como a pátria dos imigrantes, por abranger uma população cujas diversidades étnicas englobam mais de cinquenta nacionalidades ${ }^{1}$. Inicialmente, a vinda de imigrantes, nomeadamente os açorianos, a partir do século XVIII, respondia ao interesse metropolitano de ocupar as terras contra o avanço dos espanhóis no sul brasileiro².

Acompanhando o povoamento do território desde o início da colonização, houve também a imigração forçada dos negros para $\mathrm{SC}^{3}$. As primeiras populações africanas ${ }^{4}$ escravizadas se concentraram, em sua maioria, em Nossa Senhora do Desterro (atual Florianópolis), nas vilas de Nossa Senhora do Rio São Francisco (atual cidade de São Francisco do Sul) e na de Santo Antônio dos Anjos de Laguna (atual cidade de Laguna) ${ }^{5}$.

Do século XIX até metade do século XX, no contexto da abolição da escravatura e da implementação da política migratória de embranquecimento da nação, o Estado propiciou a vinda massiva de populações brancas $^{6}$ por meio da oferta de garantias e privilégios para estimular a vinda de trabalhadores europeus ${ }^{7}$. Por outro lado, verifica-se o início de um longo

\footnotetext{
${ }^{1}$ SEBRAE. Santa Catarina em números. Florianópolis: SEBRAE, 2013.

2 CORREAA, Walquíria Krüger. Considerações sobre a formação territorial e econômica de Santa Catarina. Revista GEOSUL, Florianópolis, v. 14, p. 25-44, jan./jun. 1999.

${ }^{3}$ LEITE, Ilka Boaventura. Classificações étnicas e as terras de negros no sul do Brasil. In O'DWYER, Eliane Cantarino (org.). Terra de Quilombo. Rio de Janeiro: ABA/UFRJ, 1995.

4 É necessário informar que não é possível tratar as populações de origem africana como um bloco hegemônico, formado pelos sujeitos que compartilham das marcas da escravidão, incrustadas em seu fenótipo. Desse contingente, fazem parte diversas categorias sociais, como africanos de nação, crioulos, pretos, pardos, escravizados, forros, libertos e livres, as quais se mesclam de acordo com a identidade e a realidade do sujeito. Para mais informaçcões, ver: MALAVOTA, Claudia Mortari; VIEIRA, F. A. Pretos e Pretas de Nação: tecendo vínculos e reconstruindo vidas na diáspora, Desterro, 1850/1880. Sankofa (São Paulo), v. 10, 2012, p. 101-125.

${ }^{5}$ CARDOSO, Fernando Henrique. Negros em Florianópolis: Relações sociais e econômicas. Florianópolis: Editora Insular, 2000.

6 BUENO, Alexandre Marcelo. Intolerância linguística e imigração. 184 f. Dissertação (Mestrado) Faculdade de Filosofia, Letras e Ciências Humanas, Universidade de São Paulo, São Paulo, 2006.

${ }^{7}$ Como é possível observar, a pobreza no campo e a pressão populacional, fatores associados à Revolução Industrial, acarretaram na emigração de nacionais da Europa a outras terras, principalmente às Américas.
} 
ISSN 1981-3694

(DOI): $10.5902 / 1981369433488$

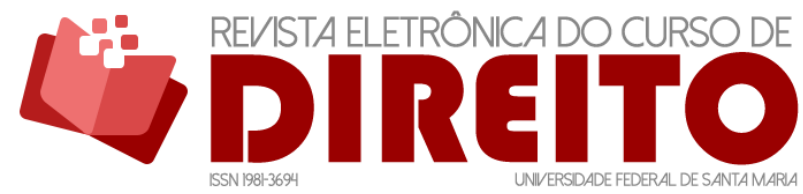

INVISIBILIZADOS NA ILHA DO DESTERRO: OS NOVOS FLUXOS DE IMIGRANTES E REFUGIADOS EM FLORIANÓPOLIS

KARINE DE SOUZA SILVA CAROLINA Nunes MIRANDA CARASEK DA ROCHA LUCAS D'AVILA

processo de obstaculização do ingresso de imigrantes negros no país e de criminalização dos corpos racializados, que teve como marco a edição do Decreto $N^{\circ} 528$ promulgado em 1890 pelo presidente Marechal Deodoro da Fonseca que proibia o ingresso de indivíduos africanos ${ }^{8}$.

Nesta conjuntura de impedimento à entrada de negros, somada à empreitada de extermínio e assimilação dos povos originários da região, Santa Catarina tornou-se um núcleo de assentamento de colônias europeias e, consequentemente, um “lócus de concretização do projeto imigrantista"9 eugênico brasileiro, baseado nas teorias racistas da época. Como consequência, o mapa demográfico atual de SC mostra que $40 \%$ da população é de ascendência alemã $^{10}$; em segundo lugar estão os descendentes de italianos, que representam cerca de $30 \%$ da população catarinense ${ }^{11}$; os negros correspondem a 15\%; em quarto lugar, em termos percentuais, estão os descendentes de eslavos, que compõem $5 \%$. Há também, em menores números, populações de origem ucraniana, austríaca, suiça, belga, grega, russa, francesa, norueguesa, sueca e dinamarquesa. Provenientes do continente asiático, notam-se sobretudo turcos, sírios, chineses e japoneses ${ }^{12}$. Ainda, o censo de $2010^{13}$ estima que o número de pessoas de etnias autóctones é de 16.041 .

O estado, todavia, não se limitou ao paradigma das primeiras correntes migratórias. No panorama dos processos globalizantes e de alteração de rotas migratórias internacionais ${ }^{14}$ a partir da década de 1980, houve uma intensificação de fluxos de nacionais do eixo sul-sul com

Para mais informações, ver: HOBSBAWM, Eric. A Era dos Extremos: o breve século XX: 1914-1991. São Paulo: Companhia das Letras, $2^{\mathrm{a}}$ ed., 1995.

8 "O Generalíssimo Manoel Deodoro da Fonseca, Chefe do Governo Provisório da Republica dos Estados Unidos do Brasil, constituído pelo Exercito e Armada, em nome da Nação:

CAPITULO I

DA INTRODUCÇÃO DE IMMIGRANTES

Art. $1^{\circ}$ É inteiramente livre a entrada, nos portos da Republica, dos indivíduos válidos e aptos para o trabalho, que não se acharem sujeitos à acção criminal do seu pais, exceptuados os indígenas da Asia, ou da África que somente mediante autorização do Congresso Nacional poderão ser admittidos de accordo com as condições que forem então estipuladas."

9 LEITE, Ilka Boaventura. Negros no Sul do Brasil: invisibilidade e territorialidade. Florianópolis: Letras Contemporâneas, 1996, p. 38.

${ }^{10}$ Suas colônias posteriormente formaram os municípios de Blumenau (1850), D. Francisca (1851) e Itajaí e Brusque (1860). IPHAN. Roteiros nacionais de imigração: Santa Catarina. Florianópolis: IPHAN, 2011.

${ }^{11}$ CORRÊA, Walquíria Krüger. Considerações sobre a formação territorial e econômica de Santa Catarina. Revista GEOSUL, Florianópolis, v. 14, p. 25-44, jan./jun. 1999.

12 LEVY, Maria Stella Ferreira. O papel da migração internacional na evolução da população brasileira (1872 a 1972). Revista de Saúde Pública, São Paulo, n. 8, 1974, p. 49-90.

${ }^{13}$ BRIGHENTI, Clóvis Antonio. Povos Indígenas em Santa Catarina. In: NOTZOLD, Ana Lúcia Vulfe; ROSA, Helena Alpini; BRINGMANN, Sandro Fernando (Org.). Etnohistória, História Indígena e educação: contribuicão para o debate. 1. ed. Porto Alegre: Palotti, 2012, p. 37-65.

14 CZAJKA, Mathias; HAAS, Hein de. The globalization of migration: Has the world become more migratory?. International Migration Review, v. 48, n. 2, 2014, p. 283-323. 
ISSN 1981-3694

(DOI): $10.5902 / 1981369433488$

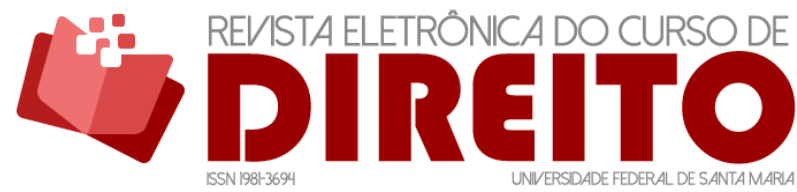

INVISIBILIZADOS NA ILHA DO DESTERRO: OS NOVOS FLUXOS DE IMIGRANTES E REFUGIADOS EM FLORIANÓPOLIS

KARINE DE SOUZA SILVA CAROLINA NunEs MiRANDA CARASEK DA ROCHA LUCAS D'AVILA

destino ao território catarinense, com destaque para os povos latino-americanos. Nota-se, então, o começo de uma mudança no perfil dos migrantes que ingressam em SC ${ }^{15}$.

Sala ${ }^{16}$ assevera que SC foi o estado que, na média entre os anos 1980 e 2000, apresentou as maiores taxas de crescimento médio anual de recepção de nacionais de países do Cone Sul ${ }^{17}$. Inicialmente, prevaleceram as migrações dos países que estão geograficamente próximos de Santa Catarina. Após, a tendência migratória diversificou o perfil quando passou a englobar nacionais da América Latina e Central, da África e do Oriente Médio, destacando-se os haitianos, senegaleses e sírios, em meio a muitas outras nacionalidades, conforme será verificado no próximo item.

Os haitianos começaram a aportar nestas terras em maior número no pós-terremoto de 2010 e, sobretudo, na sequência da Resolução Normativa $N^{\circ} 97$ do CNIg de $2012^{18}$. O Sincre ${ }^{19}$ contabilizou, no período compreendido entre 2010 e 2015, o ingresso de 28.866 imigrantes haitianos com visto permanente no Brasil; o STI ${ }^{20}$, por sua vez, apurou 85.059. Em SC, o número total de imigrantes haitianos com registro ativo, conforme os dados do Sincre no período em questão, foi de $4.395^{21}$.

Os senegaleses começaram a chegar com maior expressividade a partir de 2011, à procura de inserção laboral, como forma de escapar da desigualdade econômica e social do país. Nesse sentido, a imigração é vista como uma "estratégia de inserção profissional", que permite o envio de remessas ao exterior para o aumento da renda familiar ${ }^{22}$. Segundo Janaina Macedo, "entre 2010 e 2018, mais de 101,9 mil haitianos migraram para o Brasil e mais de sete mil e quinhentos migrantes senegaleses tiveram carteiras de trabalho expedidas"23.

\footnotetext{
15 PATARRA, Neide Lopes; BAENINGER, Rosana. Mobilidade espacial da população no Mercosul: metrópoles e fronteiras. Rev. bras. Ci. Soc., São Paulo, v. 21, n. 60, feb. 2006. p. 83-102.

16 SALA, Gabriela Adriana. Características demográficas e sócio-ocupacionais dos migrantes nascidos nos países do Cone Sul residentes no Brasil. $261 \mathrm{f}$. Tese (Doutorado) - Centro de Desenvolvimento e Planejamento Regional, Universidade Federal de Minas Gerais, Belo Horizonte, 2005.

${ }^{17}$ A autora engloba a Argentina, a Bolívia, o Chile, o Paraguai e o Uruguai como países do Cone Sul.

18 Conforme a resolução, o visto permanente passou a ser concebido aos haitianos por razões humanitárias, bem como a permanência no território brasileiro.

${ }^{19}$ Sistema Nacional de Cadastro e Registro de Estrangeiros.

${ }^{20}$ Sistema de Tráfego Internacional.

21 BAENINGER, Rosana; PERES, Roberta. Migração de crise: a migração haitiana para o Brasil. Revista Brasileira de Estudos Populares, Belo Horizonte, v.34, n.1, p.119-143, jan./abr. 2017.

22 NETO, Ramiro Januário dos Santos. Os imigrantes senegaleses na cidade de São Paulo: direitos humanos, discriminação e legislação migratória pertinente. 179 f. Dissertação (Mestrado) - Faculdade de Direito, Universidade de São Paulo, São Paulo, 2017.

${ }^{23}$ MACEDO, Janaina Santos de. Pessoas e mundos em movimento: Migrantes haitianos e senegaleses na região da Grande Florianópolis (SC). 2019. 433 f. Tese (Doutorado) - Curso de Antropologia Social, Universidade Federal de Santa Catarina, Florianópolis, 2019, p. 146.
} 
ISSN 1981-3694

(DOI): $10.5902 / 1981369433488$

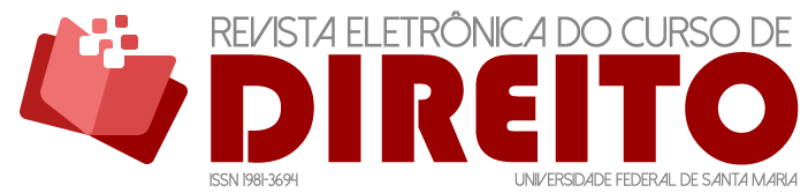

INVISIBILIZADOS NA ILHA DO DESTERRO: OS NOVOS FLUXOS DE IMIGRANTES E REFUGIADOS EM FLORIANÓPOLIS

KARINE DE SOUZA SILVA CAROLINA Nunes MiRANDA CARASEK DA ROCHA LUCAS D'AVILA

Os sírios passaram a se deslocar em grandes volumes ao Brasil a partir de 2011, com a concessão, por razões humanitárias, de visto apropriado aos indivíduos afetados pelo conflito armado. 0 número de refugiados sírios no país passou de 20 em 2010 para 2,2 mil pessoas entre 2011 e 2015, conforme o CONARE. Ademais, em 2015, estimava-se que mais de 100 famílias sírias moravam em Florianópolis ${ }^{24}$.

Dessa forma, percebe-se empiricamente que Santa Catarina possui uma grande diversidade de nacionalidades, o que se reflete também em Florianópolis. Apesar de ter sido predominantemente colonizada por açorianos, a antiga cidade do desterro é um microcosmo da multiplicidade étnica do estado. De fato, a nova face da mobilidade humana demonstra que o estado não se limitou ao padrão dos primeiros imigrantes, e que segue acolhendo coletivos das mais diferentes origens ${ }^{25}$.

No entanto, é preciso ressaltar que existe uma grande discrepância de tratamento dos imigrantes europeus vindos nos idos passados em relação aos imigrantes atuais dos eixos sul-sul. Enquanto os primeiros se beneficiaram de políticas públicas includentes e vantajosas, os últimos têm sido constantemente invisibilizados pelos poderes públicos, já que, ao parecer, não querem vê-los e nem tê-los.

Esse descaso dos poderes públicos estaduais e municipais com as novas ondas de migrações faz com que a rede de ativismo formada por diversos atores locais procure promover, na medida das suas possibilidades, ações de acolhimento e integração desses povos. Esse é o caso da Pastoral do Migrante e da Universidade Federal de Santa Catarina, que apesar das condições adversas, têm se mostrado empenhadas em visibilizar e integrar aqueles que o Poder Público ignora.

\subsection{Novos imigrantes na Grande Florianópolis}

O estado catarinense, embora seja considerado um destino assíduo de massas migratórias, até o momento não formulou políticas específicas destinadas a regularizar e a integrar as novas populações. Diante do vazio governamental, algumas instituições, como a

24 FIGUEIREDO, Carolina Ferreira de; LUNARDI, Thamirys Mendes. Diáspora e Identidade na Contemporaneidade: considerações sobre as populações árabe e muçulmana e a formação de uma comunidade em Florianópolis/SC. Revista Brasileira de História \& Ciências Sociais, [S.I], v. 8, n. 16, jul./dez. 2016.

25 PATARRA, Neide Lopes. Migrações internacionais de e para o Brasil Contemporâneo: volumes, fluxos, significados e políticas. São Paulo em Perspectiva, São Paulo, v. 19, n. 3, p. 23-33, jul./set. 2005. 
ISSN 1981-3694

(DOI): $10.5902 / 1981369433488$

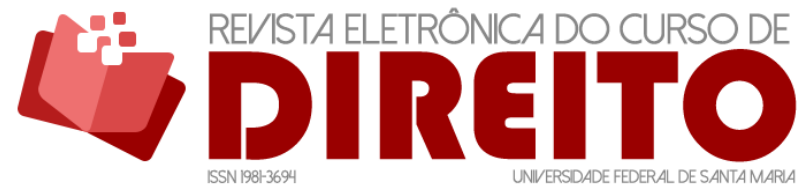

INVISIBILIZADOS NA ILHA DO DESTERRO: OS NOVOS FLUXOS DE IMIGRANTES E REFUGIADOS EM FLORIANÓPOLIS

KARINE DE SOUZA SILVA CAROLINA NunEs MiRANDA CARASEK DA ROCHA LUCAS D'AVILA

Pastoral do Migrante ${ }^{26}$ e a Universidade Federal de Santa Catarina (UFSC), passaram a protagonizar o atendimento de imigrantes e refugiados.

Recorda-se que os europeus que chegaram no século passado foram beneficiários de políticas públicas que lhes facilitaram a fixação neste território. Entretanto, o tratamento é diferenciado no caso das populações racializadas dos países do Sul Global, que são as mais vulnerabilizados em decorrência da ausência de políticas públicas de integração e acolhimento. Esta hierarquização de seres humanos é uma das caras da Modernidade eurocêntrica que produziu um mundo racial-cis-hétero-patriarcal. A invenção das raças fez com que determinados seres humanos fossem considerados superiores a outros ${ }^{27}$. A inferiorização de subjetividades é axiomática no campo das migrações, quando se nota que alguns povos são mais bem-vindos do que outros.

A falta de assistência por parte dos Poderes Públicos é herdeira da lógica ultrapassada contemporaneamente preservada na União Europeia e afiançada por setores conservadores brasileiros e catarinenses - segundo a qual os imigrantes são potenciais ameaças à segurança e, portanto, passíveis de controle, e não sujeitos de direitos. As barreiras impostas, sobretudo, aos imigrantes e refugiados de países periféricos, além de se reforçar a postura colonial, racista e hierarquizante, fomenta a disseminação da xenofobia e da intolerância ${ }^{28}$.

Diante deste panorama de marginalizações, alguns setores têm atuado de modo assertivo e têm realizado relevantes ações dedicadas a promover o acolhimento dessas populações, a encetar debates e a estimular os Poderes Públicos para elaboração e efetivação de políticas públicas. Dessas instituições, a Pastoral do Migrante, doravante Pastoral, é a que mais tem acompanhado as diferentes ondas migratórias florianopolitanas desde a década de 1990. A partir de 1996, quando foi estabelecida, a Pastoral passou a protagonizar o acolhimento de migrantes e refugiados na Grande Florianópolis. Há mais de 20 anos, a entidade tem funcionado como um polo de atração de imigrantes por promover, de maneira contínua, auxílio para regularização de residência, apoio socioeconômico, orientações sobre diversos tipos de documentação, encaminhamentos aos órgãos públicos específicos, entre outros. A longa

\footnotetext{
${ }^{26}$ A Pastoral foi homenageada pela Assembleia Legislativa do Estado de Santa Catarina (ALESC), em março de 2015, como defensora da "vida do migrante na construção de uma cultura de paz, justiça e de dignidade para toda a família humana".

27 QUIJANO, Aníbal. Coloniality and modernity-rationality. In: MIGNOLO, WALTER D.; ESCOBAR, Arturo (orgs.). Globalization and the decolonial option. New York: Routledge, 2010, p. 22-32.

28 SEBASTIANI, Luca. La colonialidad del poder y del saber em las Políticas públicas de la unión europea: Reflexiones a partir de una investigación sobre "inmigración" e "integración". Revista de Antropología Experimental, n. 15, v. 29, 2015, p. 535-552.
} 
ISSN 1981-3694

(DOI): $10.5902 / 1981369433488$

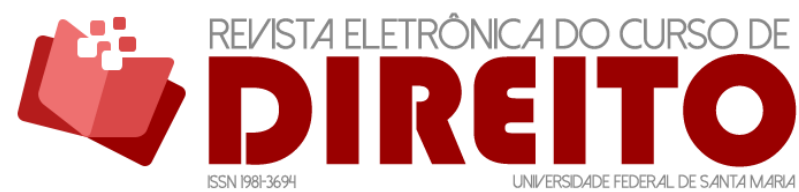

INVISIBILIZADOS NA ILHA DO DESTERRO: OS NOVOS FLUXOS DE IMIGRANTES E REFUGIADOS EM FLORIANÓPOLIS

KARINE DE SOUZA SILVA CAROLINA NunEs MiRANDA CARASEK DA ROCHA LUCAS D'AVILA

trajetória em prol dos migrantes e refugiados fez da Pastoral um centro de referência local, estadual e nacional.

Segundo os dados registrados pelo Padre Joaquim Filippin ${ }^{29}$, até 2010 a maior parte dos atendimentos realizados foi de nacionais de países do Cone Sul. Após esse período, com as mudanças nos vetores das migrações internacionais, houve uma intensificação dos fluxos advindos do Sul Global, e SC passou a se configurar como um ponto final dessas rotas mais recentes. No interstício 1997-2013 ${ }^{30}$, migrantes de 27 países $^{31}$ procuraram o suporte da Pastoral. Dentre as nacionalidades mais atendidas no período, evidenciaram-se em ordem crescente de quantidade de atendimentos: argentinos, uruguaios e paraguaios.

Ainda com base nos registros do Padre, observa-se que, a partir de 2012, novas correntes humanas, provenientes de nações que historicamente não se inseriam no âmbito das migrações brasileiras (com relação a deslocamentos não-forçados), passaram a incorporar o escopo de atenção da Pastoral. Desses, destacam-se: haitianos, e africanos de países que ainda não tinham tradição de escolha por Santa Catarina, com foco para os senegaleses, ganeses e togoleses. Ou seja, as populações negras africanas e afro-caribenhas passam a dilatar o leque das etnias atendidas.

De julho de 2013 a julho de 2015, acentuou-se o número de recém-chegados e houve uma alteração significativa na composição das nacionalidades recepcionadas pela Pastoral, agora em parceria com a UFSC. Entre os cidadãos de 27 países atendidos, os argentinos permaneceram na primeira colocação (38\%), mas a novidade foi a presença dos haitianos ${ }^{32}$, os quais ocuparam o segundo lugar (34\%), ultrapassando os uruguaios, que representaram $11 \%$ dos atendimentos ${ }^{33}$.

No início de $2015^{34}$, diante do número extraordinário de haitianos e africanos desembarcados em Santa Catarina, houve uma sobrecarrega na pequena estrutura da Pastoral, a

29 O Pe. Joaquim Filippin foi coordenador da Pastoral de 1996 a 2017.

30 Os dados não contabilizam os anos de 2002 a 2005, período em que o Pe. Joaquim Filippin se encontrava no Centro Ítalo-Brasileiro de Assistência e Instrução às Migrações, o CIBAI em Porto Alegre. Já a partir de 2013, os atendimentos, e, consequentemente, os registros dos migrantes, passaram a ser realizados pela antropóloga Tamajara Silva.

31 Os países contabilizados nos registros do Pe. Joaquim foram: Alemanha, Angola, Argentina, Bolívia, Chile, Colômbia, Congo, Cuba, Equador, Espanha, Estados Unidos, França, Gana, Guiné Bissau, Haiti, Itália, Líbia, México, Paraguai, Peru, Portugal, Rússia, Senegal, Síria, Suíça, Uruguai e Venezuela.

32 GAIRF (Grupo de Apoio ao Imigrante e Refugiado de Florianópolis e Região). Novos Imigrantes e Refugiados na Região da Grande Florianópolis: Observações preliminares sobre suas experiências e demandas. Florianópolis, 2015.

33 O relatório foi embasado nos dados coletados pela Pastoral do Migrante.

${ }^{34}$ Entre maio e junho de 2015, em decorrência de um panorama emergencial de chegada de vários ônibus enviados pelo governo acreano, os atendimentos prestados pela Pastoral/CSVM-Eirenè tiveram que ser realizados no Ginásio Capoeirão até a estabilização dos contingentes, em parceria com a Secretaria 
ISSN 1981-3694

(DOI): $10.5902 / 1981369433488$

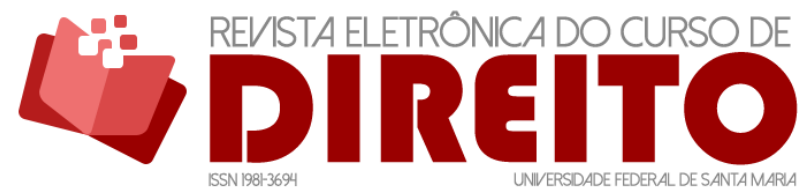

INVISIBILIZADOS NA ILHA DO DESTERRO: OS NOVOS FLUXOS DE IMIGRANTES E REFUGIADOS EM FLORIANÓPOLIS

KARINE DE SOUZA SILVA Carolina Nunes Miranda CARASEK da Rocha LUCAS D'AVILA

qual chegava a receber até 100 pessoas por dia para auxiliar em diversos temas. Neste momento, foi firmado um convênio com a Universidade Federal de Santa Catarina (UFSC) que passou a apoiar a Pastoral desde então, através do Projeto de Extensão "Cátedra Sérgio Vieira de Melo: Núcleo de Apoio a Imigrantes e Refugiados" (CSVM-Eirenè) ${ }^{35}$. Os dados estatísticos coletados a partir desta fase, e que demonstram o perfil das novas migrações para a Grande Florianópolis, serão exibidos no tópico seguinte.

\section{PERFIL DOS IMIGRANTES E REFUGIADOS ATENDIDOS ENTRE 2015 E 2017}

No atendimento diário a imigrantes e refugiados, os extensionistas e a Pastoral prestaram serviços para resolver demandas de duas áreas específicas: proteção e integração. A proteção abarca o Direito Internacional Público, o Direito Consular e Direitos Humanos, e são realizados, predominantemente, encaminhamentos para regularização migratória, solicitações de refúgio, reunião familiar, legalização de diplomas, naturalização, consulta de processos, renovação de protocolos, orientações sobre casamento, entre outros. Na esfera da integração, são realizadas ações destinadas à integração laboral, educacional e linguística, e encaminhamento para atendimento psicossocial. Quando pertinente, os imigrantes são direcionados a órgãos competentes, conforme a demanda de cada pessoa.

Durante os atendimentos, os extensionistas coletam informações que são inseridas em um banco de dados formulado pela Pastoral/CSVM-Eirenè e que têm possibilitado ilustrar um perfil dos mais novos imigrantes que habitam na Grande Florianópolis, consoante será retratado na sequência. Para este estudo, se estabelece uma delimitação temporal que corresponde aos períodos letivos 2015-2017, definido para o levantamento e a análise dos dados registrados. 0 grupo de amostragem para esta pesquisa quantitativa está circunscrita a 1783 imigrantes e refugiados ${ }^{36}$ e se referem exclusivamente àqueles que buscaram apoio da Pastoral/CSVM-Eirenè.

No período compreendido entre 2015 e 2017, a quantidade de imigrantes que solicitaram a prestação de serviços aumentou e diversificaram exponencialmente as nacionalidades, comparando-se aos períodos pregressos. O ano de 2015 foi o que apresentou a maior demanda por atendimentos já concedidos em um período anual. Devido ao grande

Municipal de Assistência Social de Florianópolis (SEMAS) e a Secretária de Estado da Assistência Social, Trabalho e Habitação SST/SC.

35 O projeto de extensão Cátedra Sérgio Vieira de Mello é uma ação do "Eirenè: Centro de pesquisas e práticas Decoloniais e Pós-Coloniais aplicadas às Relações Internacionais e ao Direito Internacional.

36 Cabe ressaltar que foram atendidos muito mais imigrantes, mas devido a inconsistências em alguns cadastros, consideraram-se apenas 1783 sujeitos à amostra. 
ISSN 1981-3694

(DOI): $10.5902 / 1981369433488$

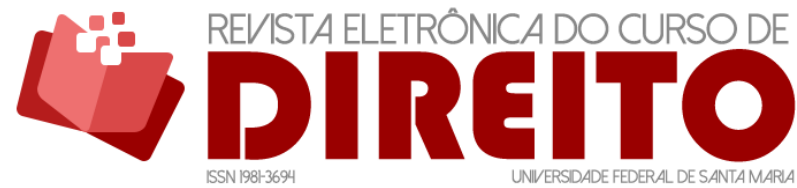

INVISIBILIZADOS NA ILHA DO DESTERRO: OS NOVOS FLUXOS DE IMIGRANTES E REFUGIADOS EM FLORIANÓPOLIS

contingente de haitianos chegados na Grande Florianópolis naquele momento, o número de pessoas atendidas diariamente, dependendo do mês, variou entre 50 a 100.

Em 2016, o fluxo continuou intenso, porém veio a apresentar uma gradativa diminuição com o passar dos meses, e se estabilizou com média de 40 a 50 pessoas por dia, a partir do segundo semestre. É interessante observar que cada indivíduo retorna em torno de cinco vezes para cada demanda. Já no ano de 2017, o montante de assistências da Pastoral/CSVM-Eirenè foi mais estável, com procura de 30 pessoas/dia, estimando mais de 5 mil atendimentos no ano ${ }^{37}$.

Nesse sentido, são expostos a seguir os dados dos cadastros e dos atendimentos realizados no período de 2015 a 2017 e que permitem, por conseguinte, apresentar as peculiaridades das novas migrações na grande Florianópolis, bem como o perfil dos imigrantes. As informações compreendem cinco categorias distintas: 1) nacionalidade; 2) escolaridade; 3) gênero; 4) faixa etária; e 5) demandas.

\subsection{Nacionalidades}

Tabela $n^{\circ} 1$ - Nacionalidades

\begin{tabular}{|c|c|c|c|c|c|c|c|}
\hline África & $\%$ & América & $\%$ & Ásia & $\%$ & \begin{tabular}{|l} 
Duropa \\
\end{tabular} & $\%$ \\
\hline Angola & $0,28 \%$ & Argentina & $5,77 \%$ & Israel & $0,17 \%$ & Alemanha & $0,06 \%$ \\
\hline Benim & $0,06 \%$ & Bolívia & $0,28 \%$ & Japão & $0,06 \%$ & Dinamarca & $0,06 \%$ \\
\hline $\begin{array}{c}\text { Cabo } \\
\text { Verde }\end{array}$ & $0,06 \%$ & Chile & $0,45 \%$ & Jordania & $0,06 \%$ & Espanha & $0,06 \%$ \\
\hline Camarões & $0,06 \%$ & Colombia & $0,90 \%$ & Síria & $0,84 \%$ & França & $0,11 \%$ \\
\hline Congo & $0,45 \%$ & Costa Rica & $0,06 \%$ & Turquia & $0,11 \%$ & Hungria & $0,06 \%$ \\
\hline Egito & $0,06 \%$ & Cuba & $0,62 \%$ & & & Itália & $0,06 \%$ \\
\hline Gana & $0,67 \%$ & Equador & $1,68 \%$ & & & Polônia & $0,06 \%$ \\
\hline $\begin{array}{l}\text { Guiné } \\
\text { Bissau }\end{array}$ & $0,34 \%$ & $\begin{array}{l}\text { Estados } \\
\text { Unidos }\end{array}$ & $0,11 \%$ & & & Portugal & $0,06 \%$ \\
\hline Líbia & $0,06 \%$ & Haiti & $78,53 \%$ & & & $\begin{array}{l}\text { Reino } \\
\text { Unido }\end{array}$ & $0,06 \%$ \\
\hline Marrocos & $0,06 \%$ & México & $0,11 \%$ & & & Rússia & $0,06 \%$ \\
\hline Nigéria & $0,17 \%$ & Paraguai & $0,45 \%$ & & & Suíça & $0,06 \%$ \\
\hline $\begin{array}{c}\text { República } \\
\text { Democrátic } \\
\text { a do Congo }\end{array}$ & $0,39 \%$ & Peru & $0,50 \%$ & & & Ucrânia & $0,11 \%$ \\
\hline Senegal & $1,46 \%$ & \begin{tabular}{|c|} 
República \\
Dominican \\
$\mathbf{a}$
\end{tabular} & $0,67 \%$ & & & & \\
\hline Serra Leoa & $0,17 \%$ & Uruguai & $2,63 \%$ & & & & \\
\hline Togo & $0,17 \%$ & Venezuela & $0,67 \%$ & & & & \\
\hline Tunísia & $0,11 \%$ & & & & & & \\
\hline
\end{tabular}

Elaboração própria (2017). Fonte: Base de dados CSVM-EIRENE/Pastoral do Migrante Florianópolis.

${ }^{37}$ A estimativa leva em consideração o período de 09 de janeiro a 20 de dezembro de 2017. 
ISSN 1981-3694

(DOI): $10.5902 / 1981369433488$

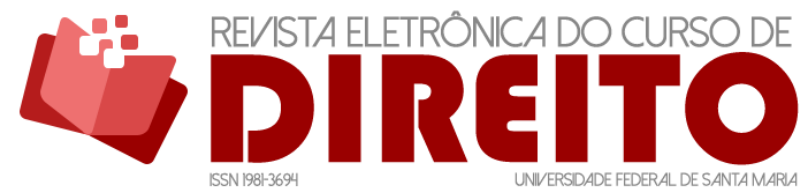

INVISIBILIZADOS NA ILHA DO DESTERRO: OS NOVOS FLUXOS DE IMIGRANTES E REFUGIADOS EM FLORIANÓPOLIS

KARINE DE SOUZA SILVA CAROLINA NunEs MiRANDA CARASEK DA ROCHA LUCAS D'AVILA

Conforme aponta a Tabela $\mathrm{n}^{\circ} 1$, a Pastoral/CSVM-Eirenè, no período compreendido entre 2015 e 2017, promoveu assistência a migrantes e refugiados de 48 nacionalidades, originárias de 4 continentes, sendo que os números mais expressivos são de nacionais de países do Sul Global. Referente ao continente africano, foram prestados atendimentos a imigrantes e refugiados de dezesseis nacionalidades, sendo que os quatro países mais expressivos numericamente foram: Senegal, Gana, República Democrática do Congo e Guiné Bissau.

Já em relação ao continente americano, foram atendidas pessoas de quinze nacionalidades, e as que se revelaram mais significativas, quantitativamente, foram: Haiti, Argentina, Uruguai e Equador. Quanto ao continente asiático, foram registrados nacionais de cinco países: Israel, Japão, Jordânia, Síria e Turquia. Em relação ao continente europeu, foram prestados auxílios a onze nacionalidades, sendo que as mais expressivas, em valores numéricos, revelaram-se França e Ucrânia.

Dentre todos os países abrangidos no escopo de atendimentos da Pastoral/CSVM-Eirenè no período relatado, citam-se os cinco coletivos que se mostraram, numericamente, mais significativos: Haiti, Argentina, Uruguai, Equador e Senegal. Tais nacionalidades, evidenciadas pela Tabela $\mathrm{n}^{\circ} 1$, vêm a indicar as novas tendências dos fluxos migratórios internacionais sul-sul nos quais a cidade de Florianópolis está inserida. E, embora se tratem de fluxos mistos, há uma grande incidência de migrantes econômicos.

Diante dos dados evidenciados pela Tabela $n^{\circ} 1$, observa-se, em primeira instância, que os migrantes haitianos representaram mais da metade dos atendimentos realizados pela Pastoral/CSVM-Eirenè entre 2015 e 2017. Com a chegada de numerosos contingentes à cidade de Florianópolis a partir de 2012, tal população, que representava o segundo maior grupo de migrantes assistidos no período anterior, tornou-se, quantitativamente, a de maior acolhida da instituição, refletindo $78,53 \%$ do total de indivíduos.

Em segundo e terceiro lugar, encontram-se, respectivamente, os migrantes argentinos e uruguaios, representando $5,77 \%$ e $2,63 \%$ dos atendimentos no período em questão. É possível observar que, em comparação com o interstício 1996-2015, tais nacionalidades passaram a comparecer com menor frequência na sede da Pastoral, se cotejados proporcionalmente com outros países, como Equador (1,68\%) e Colômbia (0,90\%). Ainda em relação aos sul-americanos, outra constatação relevante é o fato de os venezuelanos haverem se tornado, em questão de poucos meses, um novo e crescente grupo de assistidos. Os mesmos vieram a representar $0,67 \%$ do total de indivíduos cadastrados e, assim, juntamente com os nacionais da Costa Rica e de Gana, a sétima nacionalidade mais atendida da instituição. 
ISSN 1981-3694

(DOI): $10.5902 / 1981369433488$

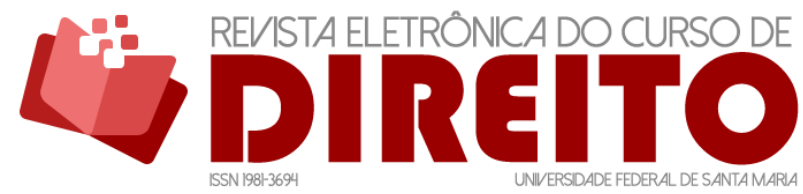

INVISIBILIZADOS NA ILHA DO DESTERRO: OS NOVOS FLUXOS DE IMIGRANTES E REFUGIADOS EM FLORIANÓPOLIS

Outrossim, verifica-se que o número de imigrantes oriundos de países do continente africano está aumentando. Se até 2015 a presença destes era de menor expressividade, no período subsequente passam a compor relevante parcela de atendimentos, o que corrobora a influência do estado catarinense nas rotas de migrações e da diáspora oriundas do Sul Global.

\subsection{Escolaridade}

Gráfico $n^{\circ} 2$ - Escolaridade

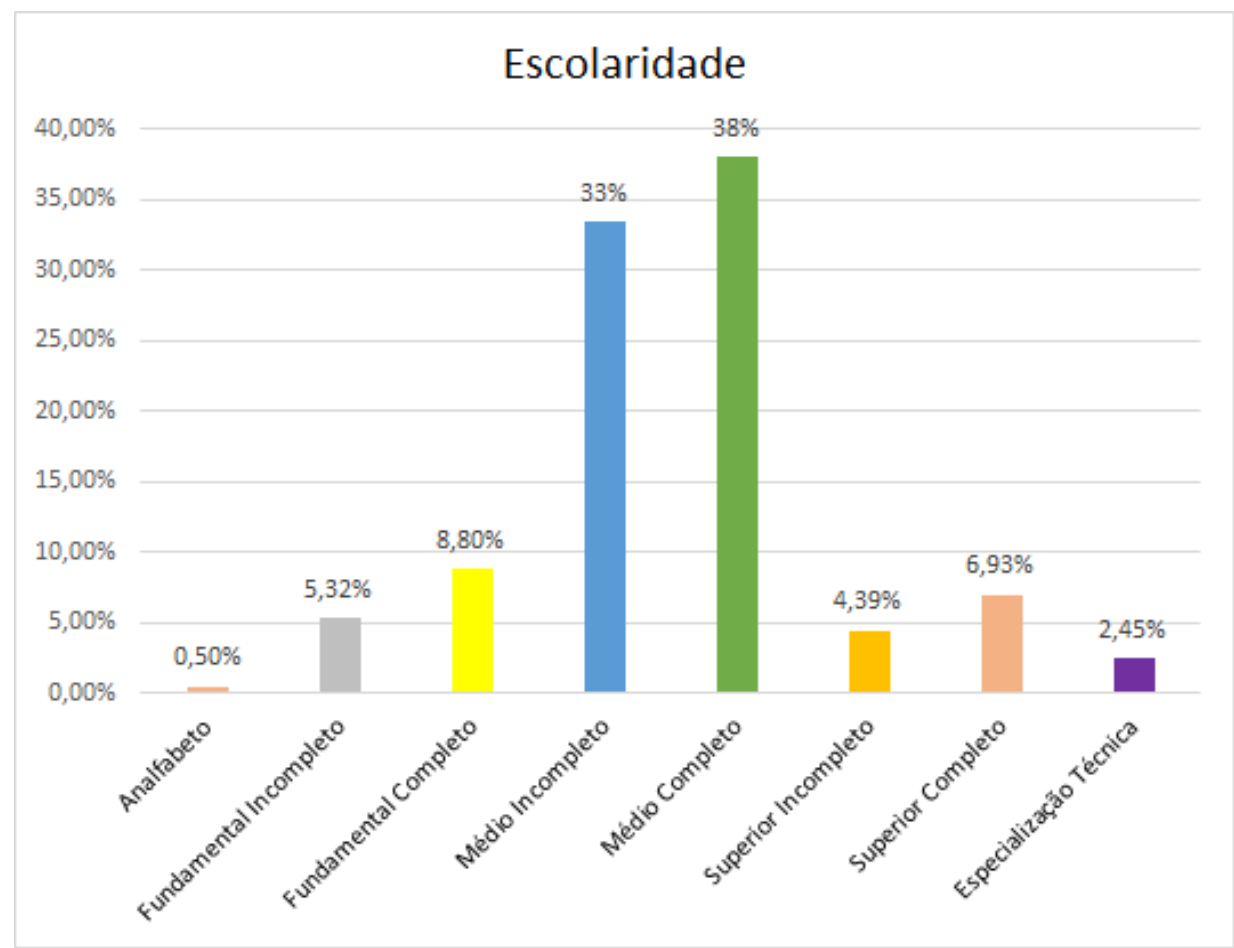

Elaboração própria (2017). Fonte: Base de dados CSVM-EIRENE/Pastoral do Migrante Florianópolis.

O Gráfico $\mathrm{n}^{\circ} 2$ expressa dados sobre a escolaridade dos imigrantes e refugiados atendidos no período em análise. Verifica-se que a maior parte deles detém algum nível de escolaridade, enquanto apenas $0,50 \%$ do total dos indivíduos classifica-se como analfabeto. As maiores proporções foram os que terminaram o ensino médio $(33,41 \%)$ ou que, pelo menos, iniciaram-no no país de origem (33\%). Em seguida, encontraram-se os migrantes cuja escolaridade se pautou no ensino fundamental, sendo esse finalizado $(8,80 \%)$ ou não $(5,32 \%)$. Por último, em números próximos aos anteriores, observaram-se aqueles que completaram o ensino 
ISSN 1981-3694

(DOI): $10.5902 / 1981369433488$

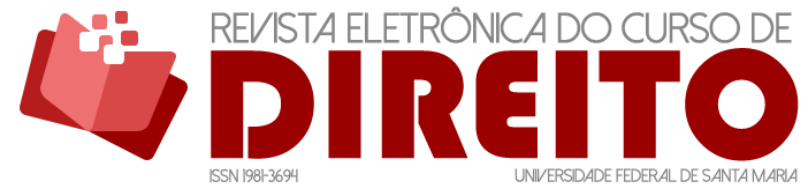

INVISIBILIZADOS NA ILHA DO DESTERRO: OS NOVOS FLUXOS DE IMIGRANTES E REFUGIADOS EM FLORIANÓPOLIS

KARINE DE SOUZA SILVA CAROLINA Nunes MiRANDA CARASEK DA ROCHA LUCAS D'AVILA

superior $(6,93 \%)$, que pelo menos o iniciaram $(4,39 \%)$ ou que detinham de especialização técnica $(2,45 \%)$.

É importante ressaltar que os diferentes sistemas de educação entre os países geram dúvida acerca da acuracidade destes percentuais, os quais podem conter relativa margem de imprecisão. Essa oscilação se deve, em parte, às discrepâncias entre os modelos de ensino do Brasil e outros países. Outro obstáculo consiste na dificuldade que muitos migrantes possuem, durante a realização do cadastro, de compreender claramente esta indagação e de respondê-la com precisão, o que se deve às barreiras linguísticas e à desconformidade dos sistemas de ensino.

\subsection{Gênero}

Gráfico $n^{\circ} 3$ - Gênero

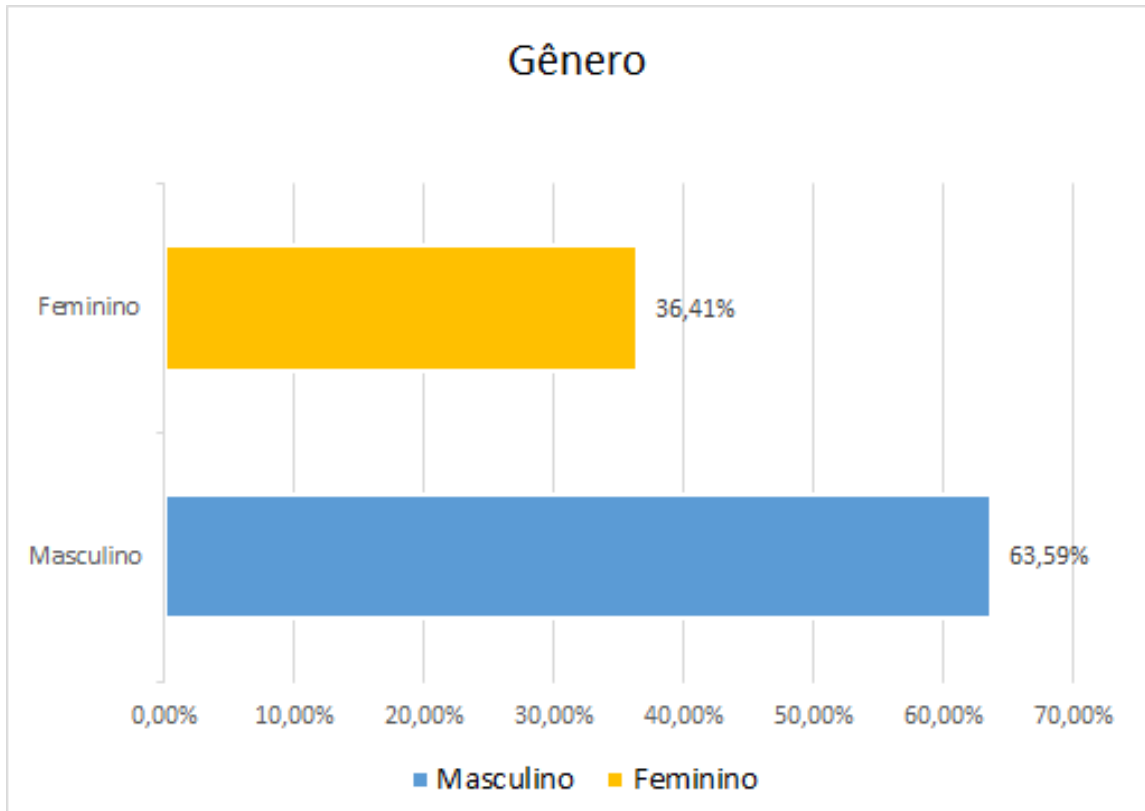

Elaboração própria (2017). Fonte: Base de dados CSVM-EIRENE/Pastoral do Migrante Florianópolis.

Consoante ao Gráfico $\mathrm{n}^{\circ} 3$, a população masculina continua sendo a mais numerosa, representando $63,59 \%$ do total de indivíduos, enquanto a feminina foi de $36,41 \%$. Todavia, em 
ISSN 1981-3694

(DOI): $10.5902 / 1981369433488$

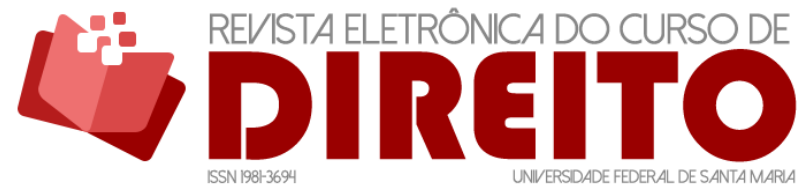

INVISIBILIZADOS NA ILHA DO DESTERRO: OS NOVOS FLUXOS DE IMIGRANTES E REFUGIADOS EM FLORIANÓPOLIS

KARINE DE SOUZA SILVA CAROLINA NunEs MiRANDA CARASEK DA ROCHA LUCAS D'AVILA

comparação com os montantes de $2013-2015^{38}$, que revelaram que $68 \%$ das pessoas correspondiam ao sexo masculino e $32 \%$ ao feminino, observa-se que esta diferença diminuiu significativamente.

A maior incidência feminina, dentre outros fatores que a motivam, tem conexão ao fato de que muitos imigrantes do sexo masculino que vieram para a região nos anos anteriores à procura de inserção no mercado laboral já se encontram estabilizados suficientemente para requerer a 'reunião familiar'39 e, desta forma, trazem seus familiares do país de origem. As populações haitianas, por exemplo, têm recorrido com muita frequência ao instituto da 'reunião familiar', tão logo que conseguem se estabelecer na cidade e conseguem demonstrar condições de provar a obtenção de meios de subsistência e capacidade financeira - que são requisitos para requerer este benefício. A unidade dos grupos familiares no Brasil sinaliza que estas coletividades estão consolidando raízes, o que incide na configuração de um novo cenário étnico e cultural florianopolitano, no qual outros idiomas e tradições somam-se aos já estabelecidos.

Outros indícios disso é o fato de que muitas nacionalidades - como os haitianos e senegaleses, grupos de maior presença no biênio 2015-2017 - passaram a organizar suas próprias festas, eventos e comemorações; marcar presença em feiras locais, onde vendem alimentos de seus países, artesanatos e performam expressões artísticas; formar suas próprias associações representativas; celebrar matrimônios de acordo com suas crenças; e procurar entidades religiosas para professarem sua fé. Tais atitudes contrastam com a ideia segundo a qual os imigrantes econômicos - aqueles os quais adentram o país primordialmente pela procura de emprego e melhores condições financeiras - são um fluxo volátil e inconstante, que não pretendem ficar e seguem para outros territórios logo estes se tornem economicamente mais viáveis ou favoráveis.

38 GAIRF (Grupo de Apoio ao Imigrante e Refugiado de Florianópolis e Região). Novos Imigrantes e Refugiados na Região da Grande Florianópolis: Observações preliminares sobre suas experiências e demandas. Florianópolis, 2015.

39 Para mais informações a respeito dos procedimentos de autorização de residência e de reunião familiar, consultar: MINISTÉRIO DA JUSTIÇA E SEGURANÇA. Autorização de Residência. 2019. Disponível em: https://www.justica.gov.br/seus-direitos/migracoes/autorizacao-de-residencia. Acesso em: 29 jul. 2019. 


\subsection{Faixa etária}

Gráfico nº 4 - Faixa Etária

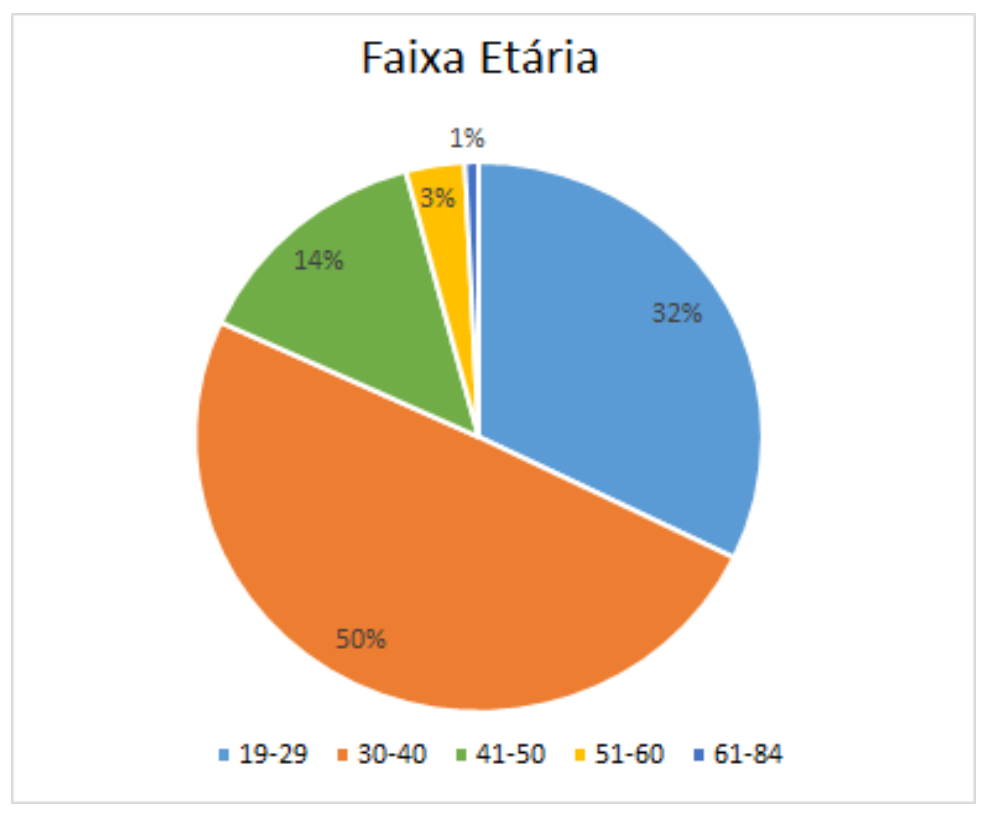

Elaboração própria (2017). Fonte: Base de dados CSVM-EIRENE/Pastoral do Migrante Florianópolis.

O Gráfico $\mathrm{n}^{\circ} 4$ revela que metade dos indivíduos assistidos pela Pastoral/CSVM-Eirenè, no período em questão, encontrava-se na faixa etária de 30 a 40 anos, enquanto que o grupo com menor frequência nos atendimentos foi o de idade superior a 61 anos. Ao se comparar tais dados com o período antecedente ${ }^{40}$, notam-se mudanças nas proporções das faixas etárias mais elevadas. Enquanto os indivíduos cuja idade entre 19 e 29 anos representaram 41\% dos migrantes, a proporção daqueles com idade entre 30 a 40 anos era de $36 \%$.

Salienta-se que não houve quantidades significativas de cadastros de menores de 19 anos que requisitaram atendimentos. A escassez de dados com relação a esta faixa etária se dá pelo fato de que estes jovens não procuram a Pastoral/CSVM-Eirenè sozinhos, já que são legalmente representados por pais ou responsáveis.

${ }^{40}$ GAIRF (Grupo de Apoio ao Imigrante e Refugiado de Florianópolis e Região). Novos Imigrantes e Refugiados na Região da Grande Florianópolis: Observações preliminares sobre suas experiências e demandas. Florianópolis, 2015. 


\subsection{Demandas}

Gráfico $n^{\circ} 5$ - Demandas

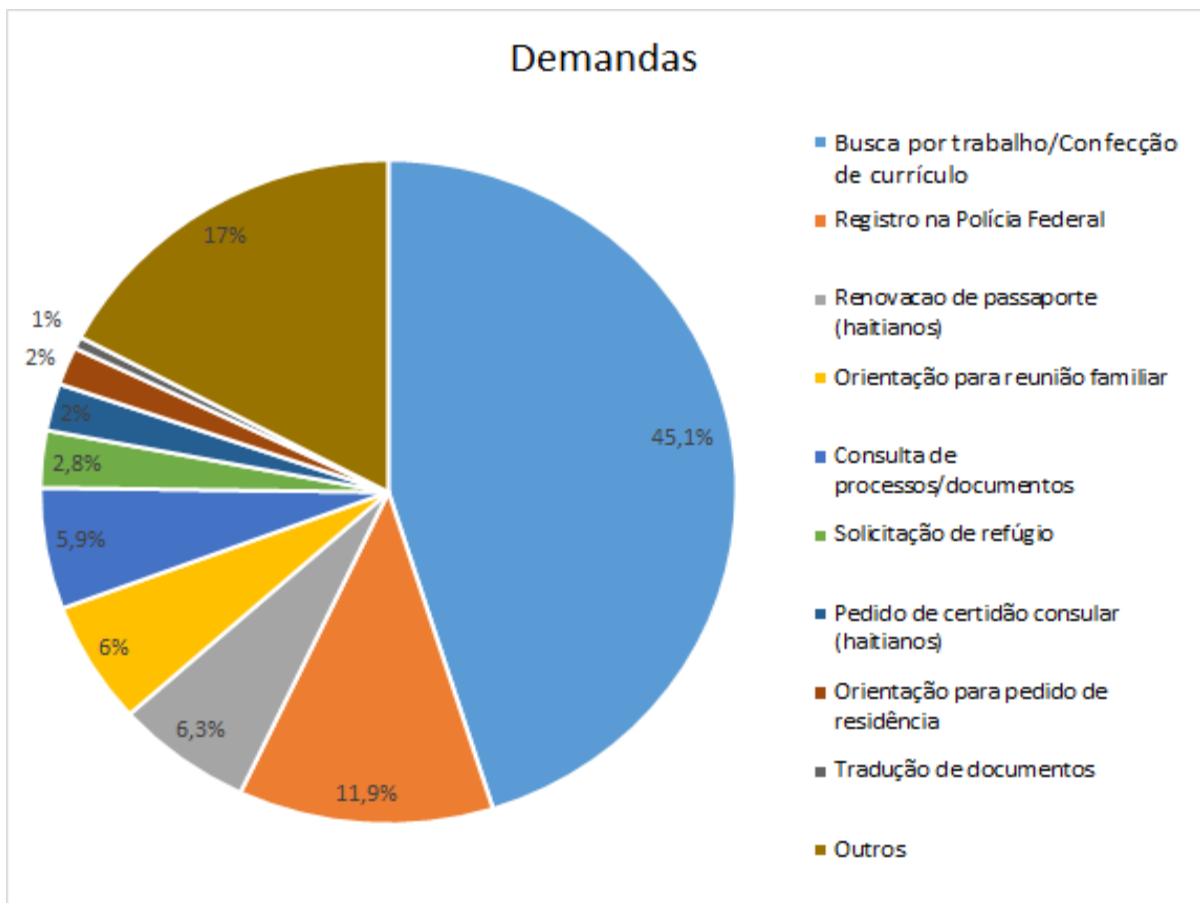

Elaboração própria (2017). Fonte: Base de dados CSVM-EIRENE/Pastoral do Migrante Florianópolis.

O Gráfico $n^{\circ} 5$ revela que as intervenções para facilitar a inserção no mercado de trabalho (o que engloba confecção e impressão de currículos) representaram praticamente metade dos atendimentos realizados pela Pastoral/CSVM-Eirenè no referido triênio. 0 Gráfico também evidencia que o segundo lugar das demandas se refere à regularização da situação migratória no Brasil. Nesse sentido, os trâmites regulatórios, como o registro na Polícia Federal, renovação de Protocolo e solicitação de refúgio e de certidão consular, consulta de processos, orientações para pedido de residência, somam 24,6\% dos atendimentos realizados. Vê-se, também, que somente o registro junto à Polícia Federal abarcou $11.9 \%$ do montante. 0 procedimento de renovação de passaporte para haitianos chegou a $6.3 \%$, os encaminhamentos destinados à reunião familiar somaram $6 \%$, e a solicitação de refúgio perfez um total de $2.8 \%$.

Além de tais serviços de caráter jurídico e burocrático, há o apoio financeiro e socioassistencial para as pessoas que se encontram em situação de maior vulnerabilidade, como a distribuição de alimentos, roupas e itens de primeira necessidade arrecadados a partir de 
ISSN 1981-3694

(DOI): $10.5902 / 1981369433488$

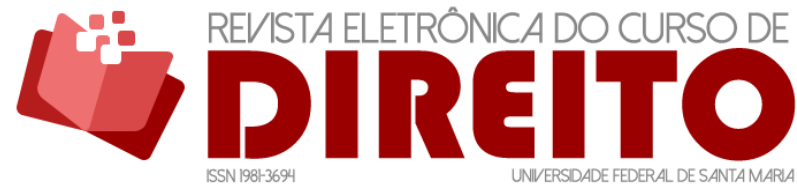

INVISIBILIZADOS NA ILHA DO DESTERRO: OS NOVOS FLUXOS DE IMIGRANTES E REFUGIADOS EM FLORIANÓPOLIS

KARINE DE SOUZA SILVA CARolina Nunes Miranda CaRASEK da Rocha LUCAS D'AVILA

ações comunitárias, além do pagamento de taxas consulares viabilizadas com o financiamento da Scalabrini International Migration Network (SIMN). Faz-se mister mencionar que o orçamento reduzido não supre a demanda total e que há alta incidência de pedidos para o pagamento de taxas e para oferta de alimentos. Na capital, há imigrantes em situação de rua, inclusive famílias inteiras, expostas a diversas violações de direitos humanos. A procura diária por prestação social revela um caráter bastante singular da migração sul-sul que é a hipervulnerabilização desses contingentes na capital de melhor padrão de vida do país.

Após a exibição das estatísticas que desenham um perfil dos imigrantes e refugiados, são formuladas algumas análises sobre as principais peculiaridades dessa migração.

\section{PARTICULARIDADES DOS NOVOS FLUXOS MIGRATÓRIOS E A CARÊNCIA DE POLÍTICAS PÚBLICAS}

A investigação sobre o perfil e as demandas da população migrante permite entender as necessidades e singularidades dessas coletividades e serve de base para o desenvolvimento de uma política migratória específica e adequada. Assim, os resultados desta pesquisa sinalizam para as peculiaridades sobre a presença dos novos imigrantes na Grande Florianópolis.

Inicialmente, é oportuno sublinhar que o estado catarinense e a sua capital ingressaram com expressividade na rota de migrações sul-sul. Em segundo lugar, é fundamental apontar que houve um incremento substancial no fluxo de africanos, que se avolumou a partir da realização da Copa do Mundo de Futebol de 2014 e das Olimpíadas de 2016, eventos que aumentaram a visibilidade do Brasil no exterior e facilitaram a concessão de vistos de ingresso via fronteiras aéreas.

Em terceiro lugar, nota-se a vinda de algumas nacionalidades, como a haitiana, dominicana, senegalesa, ganesa, congolesa e togolesa, que antes não eram tão frequentes em SC. Em quarto lugar, considerando que esta é a primeira pesquisa acadêmica que levanta dados concretos sobre a presença global dos novos imigrantes na Grande Florianópolis, pode-se aferir que há um prolongamento da condição de invisibilidade das comunidades não-brancas na historiografia de SC. Esse silenciamento se revela, também, na falta de interesse dos órgãos públicos estaduais de implantar instrumentos de coleta de dados precisos sobre a atual onda de migrações e de formular políticas públicas eficientes de acolhimento. 
ISSN 1981-3694

(DOI): $10.5902 / 1981369433488$

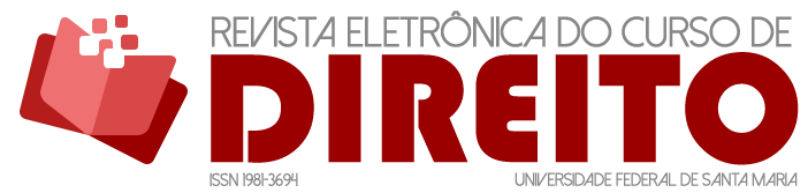

INVISIBILIZADOS NA ILHA DO DESTERRO: OS NOVOS FLUXOS DE IMIGRANTES E REFUGIADOS EM FLORIANÓPOLIS

KARINE DE SOUZA SILVA CARolina Nunes Miranda CaRASEK da Rocha LUCAS D'AVILA

Em quinto lugar, percebe-se que a maioria dos imigrantes e refugiados provém de classes sociais mais baixas e apresentam relevantes dificuldades econômicas. Os elevados números de solicitação de confecção de currículos corroboram com a ideia de que as motivações da mobilidade humana para a região e para o país são, majoritariamente, associadas a motivos econômicos, ao interesse em conseguir inserção no mercado de trabalho, em fixar-se no local de chegada e, por conseguinte, em se beneficiar de qualidade de vida mais auspiciosa. Aliás, as dificuldades à incorporação no ambiente laboral são uma das principais problemáticas enfrentadas por uma parte desse público. As barreiras para obtenção de um ofício formal fazem com que muitos indivíduos permaneçam desempregados durante longos períodos ou dependendo de trabalhos informais, o que resulta em um agravamento de suas situações de vulnerabilidade.

A falta de experiência e de formação comprovável por meio de documentos que certifiquem atividades pregressas, especializações técnicas ou graduações universitárias obtidas no país de origem são problemas que afetam os recém-chegados. Esta dificuldade diminui ainda mais as possibilidades de trabalhadores portadores de diplomas, ou com experiência anterior, de continuarem a atuar em sua área no Brasil, já não bastassem os impedimentos decorrentes das dificuldades linguísticas, e dos episódios de racismo estrutural que são cotidianos na região mais branca do país.

Entre os que possuem diploma universitário, predominantemente obtido no estrangeiro, há substanciais embaraços para validá-lo no Brasil e, consequentemente, para exercer função compatível com o grau. Ou seja, neste país, há um concreto sub-aproveitamento do potencial desses trabalhadores que, muitas vezes, são privados de exercer o direito humano ao trabalho digno devido a dificuldades de comprovação formal de experiência, validação de título, ou em decorrência da xenofobia e, sobretudo, do racismo estrutural que afeta pessoas negras, sejam brasileiras ou estrangeiras. Estes obstáculos que reverberam uma gama de transtornos para suas vítimas são, amiúde, instrumentalizados na forma de invisibilização, de rejeição e de exploração dessa mão-de-obra.

Importante mencionar que tais expressões de violência se ligam evidentemente mais ao racismo do que, propriamente, à aversão ao estrangeiro. Muito embora dezenas de nacionalidades presentes na região sofram situações de cunho xenofóbico, resta evidente que, com relação aos corpos racializados como os do Haiti e de países africanos, o racismo é a principal fonte de opressão. Tendo em vista que as populações haitianas e senegalesas despontam como as duas mais atendidas pela Pastoral/CSVM-Eirenè no período ora em apreço, esta pesquisa atestou para o fato de que a maior parte dos imigrantes e refugiados que chegam 
ISSN 1981-3694

(DOI): $10.5902 / 1981369433488$

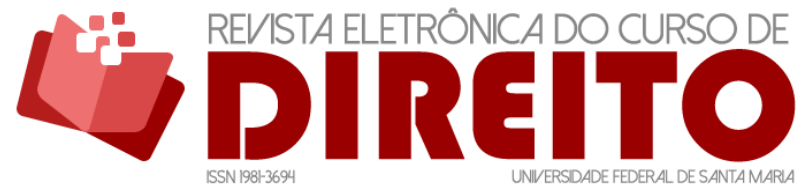

INVISIBILIZADOS NA ILHA DO DESTERRO: OS NOVOS FLUXOS DE IMIGRANTES E REFUGIADOS EM FLORIANÓPOLIS

KARINE DE SOUZA SILVA CAROLINA Nunes MIRANDA CARASEK DA ROCHA LUCAS D'AVILA

à região atualmente já enfrentou episódios de racismo e/ou injúria racial. 0 racismo, enquanto prática comportamental que infra-humaniza ${ }^{41}$ o Outro $^{42}$, é derivado da noção equivocada e ultrapassada de superioridade racial construída por longos processos de subordinação política, econômica, cultural e social, instituídos pelo colonialismo e pela Modernidade e que ainda sobrevivem vigorosamente na sociedade por meio da colonialidade do ser, do saber e do poder ${ }^{43}$. Por isso, é necessária uma atuação contundente dos poderes públicos para combater o racismo e preservar os direitos humanos das pessoas racializadas.

\section{CONCLUSÃO}

A investigação realizada com os imigrantes e refugiados atendidos pela Pastoral/CSVMEirenè permitiu diagnosticar uma série de características que permearam estas correntes migratórias entre 2015 e 2017. O aumento das populações provenientes de países periféricos, que inseriu SC definitivamente nas migrações do eixo sul-sul, tem produzido um ambiente de riqueza étnica jamais presenciado, ao mesmo tempo em que impõe desafios que são relacionados às especificidades desses contingentes.

Estas alterações demandam uma ação assertiva do poder público diante da reconfiguração étnica e demográfica da Grande Florianópolis, na qual novos costumes e idiomas somam-se às tradições culturais já estabelecidas pelos antigos "desterrados" que foram, como se sabe, muito bem-acolhidos na antiga cidade do Desterro. Essa tarefa é urgente, tendo em vista que os imigrantes e refugiados não-brancos do Sul, ao serem invisibilizados, tornam-se hipervulnerabilizados diante da inação do poder público que os expõe aos processos de exclusão social. Ou seja, não se trata de pessoas vulneráveis. Esses coletivos são vulnerabilizados devido, sobretudo, à ausência de políticas públicas estaduais e municipais inclusivas.

A inércia de atuação do Poder Público reforça a herança colonial que mantém estruturas hierarquizadas de poder e nega as historicidades não-hegemônicas. Pela ótica colonial, o migrante do Sul Global é visto como cidadão de segunda categoria, detentor de "menos direitos”, ou seja, é submetido a marcadores de subalternidade, como raça, língua e religião,

\footnotetext{
${ }^{41}$ Conceito de Paul Gilroy para denominar os subalternizados pela escravidão e pela raciologia. "o humano e o infra-humano emergiram juntos e a raça é a linha entre eles”. GILROY, Paul. Entre Campos. Nações, culturas e fascínio da raça. São Paulo: Annablume,2009, p. 67.

42 GILROY, Paul. Entre Campos. Nações, culturas e fascínio da raça. São Paulo: Annablume, 2009.

43 QUIJANO, Aníbal. Colonialidade do Poder e Classificação Social. In: SANTOS, Boaventura de Sousa; MENESES, Maria. Epistemologias do Sul. Coimbra: Almedina S.a., 2009, p. 73-114.
} 
ISSN 1981-3694

(DOI): $10.5902 / 1981369433488$

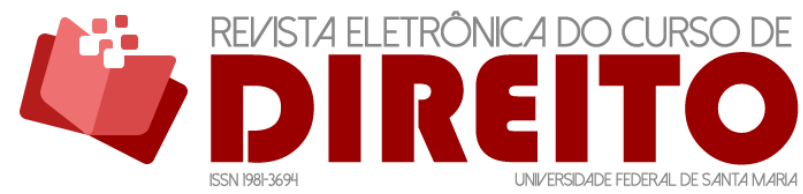

INVISIBILIZADOS NA ILHA DO DESTERRO: OS NOVOS FLUXOS DE IMIGRANTES E REFUGIADOS EM FLORIANÓPOLIS

KARINE DE SOUZA SILVA CAROLINA Nunes MIRANDA CARASEK DA ROCHA LUCAS D'AVILA

que o inferiorizam diante dos demais indivíduos. É dever do Estado cessar a propagação dessa estrutura excludente, promover a formação de espaços de convivência não-hierarquizados e incluir essas pessoas nos arranjos institucionais para que possam, efetivamente, ser e existir de maneira digna.

A ausência governamental gera um sobrecarregamento das iniciativas acadêmicas e civis, as quais, no lugar de meras colaboradoras e auxiliares, acabam por se ver encarregadas de desempenhar todo o trabalho de acolhida sozinhas. Faz-se mister, por fim, reconhecer a importância da cooperação Pastoral/UFSC. Ainda que este protagonismo decorra da insuficiência de atitudes dos entes estadual e municipal, a parceria se tornou uma referência não só no âmbito regional, mas também no nacional e internacional. Dessa forma, a atuação conjunta tem sido fundamental para o acolhimento diário a estas populações, uma vez que tem preenchido as lacunas deixadas pela inércia do Poder Público na integração de migrantes e refugiados dos países do Sul Global.

\section{REFERÊNCIAS}

BAENINGER, Rosana; PERES, Roberta. Migração de crise: a migração haitiana para o Brasil.

Revista Brasileira de Estudos Populares, Belo Horizonte, v.34, n.1, p.119-143, jan./abr. 2017.

BRIGHENTI, Clóvis Antonio. Povos Indígenas em Santa Catarina. In: NOTZOLD, Ana Lúcia Vulfe; ROSA, Helena Alpini; BRINGMANN, Sandro Fernando (Org.). Etnohistória, História Indígena e educação: contribuição para o debate. 1. ed. Porto Alegre: Palotti, 2012.

BUENO, Alexandre Marcelo. Intolerância linguística e imigração. 184 f. Dissertação (Mestrado) Faculdade de Filosofia, Letras e Ciências Humanas, Universidade de São Paulo, São Paulo, 2006.

CARDOSO, Fernando Henrique. Negros em Florianópolis: Relações sociais e econômicas. Florianópolis: Editora Insular, 2000.

CORRÊA, Walquíria Krüger. Considerações sobre a formação territorial e econômica de Santa Catarina. Revista GEOSUL, Florianópolis, v. 14, p. 25-44, jan./jun. 1999.

CZAJKA, Mathias; HAAS, Hein de. The globalization of migration: Has the world become more migratory?. International Migration Review, v. 48, n. 2, 2014.

FIGUEIREDO, Carolina Ferreira de; LUNARDI, Thamirys Mendes. Diáspora e Identidade na Contemporaneidade: considerações sobre as populações árabe e muçulmana e a formação de uma comunidade em Florianópolis/SC. Revista Brasileira de História \& Ciências Sociais, [S.I], v. 8, n. 16, jul./dez. 2016. 
ISSN 1981-3694

(DOI): $10.5902 / 1981369433488$

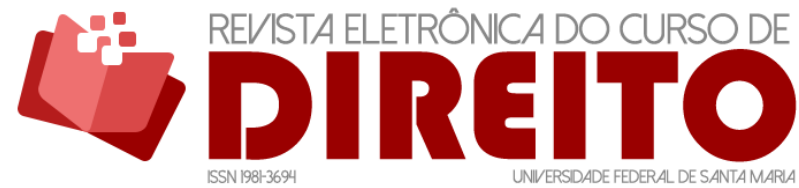

INVISIBILIZADOS NA ILHA DO DESTERRO: OS NOVOS FLUXOS DE IMIGRANTES E REFUGIADOS EM FLORIANÓPOLIS

KARINE DE SOUZA SILVA CAROLINA Nunes MIRANDA CARASEK DA ROCHA LUCAS D'AVILA

GAIRF (Grupo de Apoio ao Imigrante e Refugiado de Florianópolis e Região). Novos Imigrantes e Refugiados na Região da Grande Florianópolis: Observações preliminares sobre suas experiências e demandas. Florianópolis, 2015.

GILROY, Paul. Entre Campos. Nações, culturas e fascínio da raça. São Paulo: Annablume, 2009.

LEITE, Ilka Boaventura. Classificações étnicas e as terras de negros no sul do Brasil. In O’DWYER, Eliane Cantarino (org.). Terra de Quilombo. Rio de Janeiro: ABA/UFRJ, 1995.

LEITE, Ilka Boaventura. Negros no Sul do Brasil: invisibilidade e territorialidade. Florianópolis: Letras Contemporâneas, 1996.

LEVY, Maria Stella Ferreira. O papel da migração internacional na evolução da população brasileira (1872 a 1972). Revista de Saúde Pública, São Paulo, n. 8, 1974.

MACEDO, Janaina Santos de. Pessoas e mundos em movimento: Migrantes haitianos e senegaleses na região da Grande Florianópolis (SC). 2019. 433 f. Tese (Doutorado) - Curso de Antropologia Social, Universidade Federal de Santa Catarina, Florianópolis, 2019.

NETO, Ramiro Januário dos Santos. Os imigrantes senegaleses na cidade de São Paulo: direitos humanos, discriminação e legislação migratória pertinente. 179 f. Dissertação (Mestrado) Faculdade de Direito, Universidade de São Paulo, São Paulo, 2017.

PATARRA, Neide Lopes. Migrações internacionais de e para o Brasil Contemporâneo: volumes, fluxos, significados e políticas. São Paulo em Perspectiva, São Paulo, v. 19, n. 3, p. 23-33, jul./set. 2005.

PATARRA, Neide Lopes; BAENINGER, Rosana. Mobilidade espacial da população no Mercosul: metrópoles e fronteiras. Rev. bras. Ci. Soc., São Paulo, v. 21, n. 60, feb. 2006.

QUIJANO, Aníbal. Colonialidade do Poder e Classificação Social. In: SANTOS, Boaventura de Sousa; MENESES, Maria. Epistemologias do Sul. Coimbra: Almedina S.a., 2009.

QUIJANO, Aníbal. Coloniality and modernity-rationality. In: MIGNOLO, WALTER D.; ESCOBAR, Arturo (orgs.). Globalization and the decolonial option. New York: Routledge, 2010.

SALA, Gabriela Adriana. Características demográficas e sócio-ocupacionais dos migrantes nascidos nos países do Cone Sul residentes no Brasil. $261 \mathrm{f}$. Tese (Doutorado) - Centro de Desenvolvimento e Planejamento Regional, Universidade Federal de Minas Gerais, Belo Horizonte, 2005.

SEBASTIANI, Luca. La colonialidad del poder y del saber em las Políticas públicas de la unión europea: Reflexiones a partir de una investigación sobre "inmigración" e "integración". Revista de Antropología Experimental, n. 15, v. 29, 2015.

SEBRAE. Santa Catarina em números. Florianópolis: SEBRAE, 2013. 


\section{COMO FAZER REFERÊNCIA AO ARTIGO (ABNT):}

SILVA, Karine de Souza; ROCHA, Carolina Nunes Miranda Carasek da; D'AVILA, Lucas. Invisibilizados na ilha do desterro: os novos fluxos de imigrantes e refugiados em Florianópolis. Revista Eletrônica do Curso de Direito da UFSM, Santa Maria, RS, v. 15, n. 1, e33488, jan./abr. 2020. ISSN 1981-3694. DOI: http://dx.doi.org/10.5902/1981369433488. Disponível em: https://periodicos.ufsm.br/revistadireito/article/view/33488 Acesso em: dia mês. ano.

Direitos autorais 2020 Revista Eletrônica do Curso de Direito da UFSM

Editores responsáveis: Rafael Santos de Oliveira e Angela Araujo da Silveira Espindola

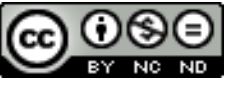

Esta obra está licenciada com uma Licença Creative Commons Atribuição-NãoComercial-SemDerivações 4.0 Internacional.

\section{SOBRE OS/AS AUTORES/AS}

\section{KARINE DE SOUZA SILVA}

Professora dos Programas de Pós-graduação stricto sensu em Relações Internacionais e em Direito da Universidade Federal de Santa Catarina. Pesquisadora Produtividade em Pesquisa PQ CNPq. É titular da Cátedra Jean Monnet - outorgada oficialmente pela União Europeia - e da Cátedra Sérgio Vieira de Mello da Agência das Nações Unidas para Refugiados. É vicecoordenadora do Curso de Graduação em Relações Internacionais. Realizou Estágio pós-doutoral no "Institute for International and European Policy" da Katholieke Universiteit Leuven e Estágio Sênior na Université Libre de Bruxelles, Bélgica. Doutora e Mestre em Direito (com concentração em Relações Internacionais) pela Universidade Federal de Santa Catarina; Fez Estágio Doutoral na Universidad de Sevilla /Espanha. Fez Pós-graduação lato sensu em Integração Regional na Universidad Internacional de Andalucía, Espanha. Realizou visita-estágio no Tribunal de Justiça da União Européia, em Luxemburgo e no Parlamento Europeu, em Bruxelas. Professora visitante da Universidade Técnica de Moçambique, da Universidade do Minho, em Portugal, da Université Libre de Bruxelles, na Bélgica, e da Universidad de Valladolid, Espanha. Consultora ad hoc do CNPq, da CAPES, da FAPESC, do MEC e da União Europeia. Participou como observadora da Missão das Nações Unidas para estabilização do Haiti (MINUSTAH). É coordenadora do "EIRENÉ - Centro de Pesquisas e práticas Decoloniais e Pós-coloniais aplicadas às Relações Internacionais e ao Direito Internacional" - e do projeto de extensão "Apoio a Imigrantes e Refugiados" (NAIR/Eirenè/UFSC). Tem experiência na área de Epistemologias do Sul, abordagens Pós-coloniais e Decoloniais aplicadas ao Direito Internacional e às Relações Internacionais, com ênfase em: 1) Escravidão, Colonialismo, África e as Relações Internacionais; 2) Organizações Internacionais, Direito Internacional Humanitário e Direitos Humanos; 3) Diáspora africana, raça, migrações e refúgios; 4) Raça e a descolonização do Direito Internacional e das Relações Internacionais; 5) Missão das Nações Unidas para estabilização do Haiti (MINUSTAH);. Homepage: http://irene.ufsc.br/

\section{CARolina Nunes Miranda CaRasek da Rocha}

Possui graduação em Relações Internacionais pela Universidade Federal de Santa Catarina (2016) e em Direito pela Universidade do Sul de Santa Catarina (2016). Mestranda em Direito e Relações Internacionais, pelo Programa de PósGraduação em Direito da Universidade Federal de Santa Catarina. Pesquisadora do grupo Eirenè "Centro de Pesquisas e Práticas Pós-coloniais e Decoloniais aplicadas às Relações Internacionais e ao Direito Internacional". Extensionista do NAIR "Núcleo de Apoio aos Imigrantes e Refugiados", vinculado ao Eirenè. Tem experiência na área de Direito, com ênfase em Direito Internacional Público e em Relações Internacionais, com ênfase em Direitos Humanos, Direito dos Refugiados, Organizações Internacionais e Migração.

\section{LUCAS D'AVILA}

Graduando do curso de Relações Internacionais pela Universidade Federal de Santa Catarina (UFSC). Pesquisador e membro do Centro de Pesquisas e Práticas Decoloniais e Pós-Coloniais aplicadas às Relações Internacionais e ao Direito Internacional (EIRENÈ). Bolsista de extensão PROBOLSA do Núcleo de Apoio a Imigrantes e Refugiados da região de Florianópolis (NAIR). 